\title{
Desigualdade, escala e políticas públicas: uma análise espacial dos equipamentos públicos nas favelas cariocas
}

\author{
Inequality, scale and public policy: a spatial analysis of public services in Rio de Janeiro's \\ slums
}

Camila Carvalho[a.b] (ㄷ), Fania Fridman[c], Julia Strauch[d,e]

\author{
[a] Universidade Federal Fluminense (UFF), Niterói, RJ, Brasil \\ [b] Centro Universitário Redentor, Paraíba do Sul, RJ, Brasil \\ [c] Instituto de Pesquisa e Planejamento Urbano e Regional (IPPUR), Rio de Janeiro, RJ, Brasil \\ [d] Escola Nacional de Ciências Estatísticas (ENCE), Rio de Janeiro, RJ, Brasil \\ [e] Universidade do Estado do Rio de Janeiro (UERJ), Rio de Janeiro, RJ, Brasil
}

Como citar: Carvalho, C., Fridman, F., \& Strauch, J. (2019). Desigualdade, escala e políticas públicas: uma análise espacial dos equipamentos públicos nas favelas cariocas. urbe. Revista Brasileira de Gestão Urbana, 11, e20180053. https://doi.org/10.1590/2175-3369.011.002.A004

\section{Resumo}

A literatura que relaciona políticas públicas com a estrutura socioespacial urbana mostra que, ao concentrar investimentos em áreas de mais alta renda, o Estado reforça as desigualdades, em vez de mitigá-las. Conhecida como "causação circular", essa dinâmica é geralmente estudada com base na comparação entre os bairros de uma cidade. Nesse tipo de análise, os bairros de classe média e médiaalta emergem como áreas reiteradamente valorizadas pelos investimentos públicos, em detrimento dos bairros pobres da cidade, incluindo as favelas. Neste artigo, testamos a hipótese de que essa dinâmica não é exclusiva da escala da cidade, podendo ser observada também na escala do bairro. Para isso, analisamos a localização dos equipamentos e serviços públicos dentro das três maiores favelas da cidade do Rio de Janeiro, buscando correlacionar essa localização com a condição socioeconômica dos moradores. Utilizando os dados do Censo Demográfico 2010 agregados por setor censitário, esta análise mostra uma concentração de equipamentos e serviços nas áreas de mais alta renda de cada favela, sugerindo um processo análogo ao que é observado na cidade como um todo.

Palavras-chave: Favelas. Pobreza. Políticas públicas. Estado.

\section{Abstract}

In the literature on the relationships between public policies and urban social structure, several works show that, by concentrating investments in higher-income areas, the State reinforces inequalities instead of alleviating them. Known as "circular causation", this dynamic is generally studied through the comparison between neighborhoods within a city. In this kind of analysis, the middle class and upper middle class neighborhoods emerge as areas repeatedly valued by public investments, to the detriment of poorest neighborhoods of the city, favelas included. In this paper, the intention is to check the hypothesis

CC é mestre em Planejamento Urbano e Regional, e-mail: lsc.camila@gmail.com

FF é doutora em Economia Política, e-mail: fania.fridman@gmail.com

JS é doutora em Engenharia de Sistemas e Computação, e-mail: julia.strauch@ibge.gov.br 
that this dynamic is not inherent to the city scale, as it can also be observed on the neighborhood scale. For this, it was analyzed the spatial relations between public services and the socio-economic areas of Rio de Janeiro's three largest favelas. Using 2010 Demographic Census data at the census tract level, the analysis shows the concentration of services in the higher income areas in each favela, suggesting a process analogous to the one operating at citywide scale.

Keywords: Slums. Poverty. Public policy. State.

\section{Introdução}

Na estrutura urbana das cidades brasileiras é possível observar uma série de obras de infraestrutura que tendem a se concentrar em áreas de mais alta renda. No caso do Rio de Janeiro, essa concentração é observada na Zona Sul e na porção da orla marítima da Zona Oeste (Barra da Tijuca) ${ }^{1}$ (Carvalho, 2017).

Entretanto, até o momento tem sido pouco explorado na literatura como a espacialização dos investimentos públicos se dá nas áreas habitadas pelos mais pobres. A hipótese deste trabalho é a de que nas favelas a concentração de investimentos é análoga à observada na cidade como um todo. Ou seja, há uma concentração de equipamentos e serviços nas localidades destes territórios onde vivem pessoas com renda superior à dos demais moradores. Neste sentido, as políticas públicas implementadas nestas áreas (por meio de fornecimento de equipamentos e serviços) estariam ali concentradas, reforçando a reprodução da desigualdade socioespacial nesta escala de análise.

Essa suspeita anuncia a seguinte construção do problema: estariam as políticas territoriais de combate à pobreza urbana de fato reduzindo a pobreza e a desigualdade ou apenas reforçando-as? Esta questão contraintuitiva aborda um aspecto da complexidade das intervenções, de forma a incluir possíveis "consequências não intencionadas" (Schelling, 1978), opostas às intenções originais e aparentemente não exploradas na literatura até o momento.

Por isso, o argumento central deste trabalho é a necessidade de problematizar a espacialidade interna dessas áreas: o fato de que os lugares de um bairro precarizado ou de uma favela não são igualmente pobres. Essa problematização envolve explorar e reconhecer as diferenciações na microescala dos bairros. Trabalhos como o de Fowler (2016) mostram a importância de estudar fenômenos complexos na microescala - como a segregação, por exemplo.

O objetivo desta pesquisa é, portanto, compreender a pobreza urbana quanto à sua espacialidade, identificando se os investimentos públicos em equipamentos e serviços nas favelas estariam concentrados nas áreas de mais alta renda, tal como acontece na escala da cidade. Este argumento contribui para a discussão e amplia o debate sobre a visão hegemônica homogeneizante dos lugares pobres.

Os estudos de caso aqui apresentados foram pautados em três favelas de diferentes zonas da cidade do Rio de Janeiro: Rocinha (Zona Sul), Complexo do Alemão (Zona Norte) e Fazenda Coqueiro (Zona Oeste). Utilizando o método da análise espacial com os dados do Censo Brasileiro de 2010 e da Prefeitura da Cidade do Rio de Janeiro, buscamos mostrar que a concentração de equipamentos e serviços nas favelas estudadas se concentram nas áreas de mais alta renda, reproduzindo o padrão encontrado na escala da cidade.

\footnotetext{
${ }^{1}$ Este processo de concentração de investimentos na orla marítima do Rio de Janeiro é histórico. Por exemplo, no período 1975-77, 60\% dos investimentos em água e esgoto foram alocados na área correspondente às Zonas Sul, Norte e Centro, incluindo a Barra da Tijuca, que em 1970 já apresentava 83\% dos domicílios ligados à rede de água e 77\%, à rede de esgoto. Na Zona Oeste, os percentuais não passavam de 78\% e 14\%, respectivamente (Vetter \& Massena, 1982; Lago, 2000).
} 


\section{O padrão de concentração de investimentos nas áreas de mais alta renda nas cidades}

Nos estudos urbanos, diversas pesquisas relacionam as ações do Estado à estrutura socioespacial urbana. Em uma perspectiva histórica, ao analisar a estruturação urbana do Rio de Janeiro, Abreu (2008, p. 15) argumenta que "[...] o Estado tem tradicionalmente apoiado os interesses e privilégios das classes e grupos sociais dominantes, via adoção de políticas, controles e mecanismos altamente discriminatórios e elitistas".

Alguns autores demonstraram que houve um processo de "reinvestimento" em áreas que já contavam com infraestrutura prévia, como o faz Lago (2000, p. 49). Segundo a autora, os investimentos eram

[...] alocados privilegiadamente nos locais onde o retorno do capital investido estivesse garantido via impostos e tarifas, justificando a concentração dos recursos nas áreas valorizadas já servidas de infraestrutura e equipamentos urbanos.

Vetter \& Massena (1982) se apropriaram do conceito de causação circular cumulativa proposto por Myrdal (1957), aplicando-o à escala urbana e argumentando que as obras de infraestrutura tendem a beneficiar os proprietários de terra, já que a intervenção do Estado valoriza os terrenos. Assim,

[...] no caso do Brasil, onde a distribuição de poder econômico e político é muito desigual, um dos resultados desse processo de causação circular é que os menos privilegiados acabam morando na periferia geralmente menos dotada de infraestrutura e de outros serviços coletivos, enquanto os grupos mais privilegiados se situam em áreas com melhores níveis de consumo coletivo (Vetter \& Massena, 1982, p. 70).

O mecanismo da causação circular seria capaz de aumentar as rendas dos estratos superiores da sociedade, enquanto diminui a renda dos grupos de mais baixa renda. Segundo Lago (2000, p. 38), a desigual distribuição espacial dos investimentos públicos em infraestrutura e equipamentos coletivos é consequência da "[...] maior capacidade política das camadas superiores".

Em seu trabalho sobre o espaço intraurbano brasileiro, Villaça (1998) também reforça o argumento de que nas áreas da cidade onde moram as camadas de maior renda há uma concentração de equipamentos urbanos e serviços. 0 autor chama a atenção para o poder destas camadas em trazer investimentos para seus locais de moradia. Assim, quando conseguem, "[...] mais vantajosa essa região se torna para aquelas camadas e mais difícil se torna, para elas, abandonar essa direção de crescimento" (Villaça, 1998, p. 321).

Tal situação não se restringe aos países capitalistas menos desenvolvidos. Ao estudar diversas cidades do mundo, Kilroy (2009) trata da competição por investimento público entre as camadas sociais.

Em muitas cidades, a distribuição espacial dos indicadores de bem-estar é causada não só pelas desigualdades espaciais na renda: é impregnada pelas distribuições espaciais regressivas do investimento público. Uma de suas causas mais influentes seria a competição pelo investimento público em serviços e amenidades da qual os grupos de renda mais alta tendem a ganhar (Kilroy, 2009, p. 18, tradução nossa).

É importante frisar que tais investimentos públicos não estão apartados do tema da valorização do solo. Harvey (1982) argumenta que a tentativa de preservação, ou mesmo de elevação, do valor da propriedade privada também ocorre com a classe trabalhadora. Para o autor,

Todo proprietário de habitação, quer goste ou não, é aprisionado numa luta pela apropriação de valores por causa dos flutuantes padrões de custos e benefícios externos produzidos no ambiente construído. Uma nova avenida pode destruir o valor de algumas habitações e elevar o valor de outras, o mesmo se aplica a todos os tipos de novos empreendimentos urbanos, renovações, obsoletismo acelerado, etc (Harvey, 1982, p. 14).

Assinalamos que estas teorias se debruçam sobre a escala de análise da cidade. A questão de interesse neste trabalho se relaciona diretamente com a possibilidade de replicação dessa lógica na escala das áreas 
pobres. Ou seja, também nos bairros pobres ou favelas podem existir grupos com maior poder político e econômico que conseguem atrair intervenções urbanísticas com a justificativa de melhorar condições de vida da população local.

Com os dados sistematizados, ainda que não seja possível revelar se os grupos dominantes locais são responsáveis pelo "reinvestimento" do Estado em certas porções do território, procuramos entender aqui se os mecanismos que reproduzem a desigualdade na escala da cidade se replicam em outra escala. Uma escala pouco usual nos estudos urbanos: a microescala ${ }^{2}$ da favela.

Associado à necessidade de reconhecer a estrutura socioespacial em pequenas porções do território, como bairros e favelas, está o estudo de onde as políticas urbanas estão sendo implantadas. Trata-se de compreender se os recursos despendidos nos últimos anos em políticas de combate e de mitigação dos efeitos da desigualdade urbana estariam sendo empregados para trazer melhorias nas condições de vida dos pobres urbanos ou reforçando a desigualdade na microescala.

\section{Materiais e métodos}

\section{Dados}

Os dados sobre a localização e quantidade dos equipamentos foram levantados junto à Prefeitura da Cidade do Rio de Janeiro (Rio de Janeiro, 2016). Consideramos os seguintes equipamentos e serviços3: escolas, unidades de saúde, praças, Unidades de Polícia Pacificadora (UPP), estações do teleférico, Praças do Conhecimento, Postos de Observação Urbanística e Social (POUSO) e os empreendimentos do Programa Minha Casa Minha Vida4 (PMCMV). 0 levantamento da localização equipamentos foi feito a partir da base digital da Prefeitura. Depois fez-se a consulta nas secretarias ${ }^{5}$ correspondentes para obter mais informações sobre cada equipamento.

Os dados econômicos, assim como a base cartográfica, são provenientes do Censo 2010, fornecidos pelo Instituto Brasileiro de Geografia e Estatística (IBGE) ${ }^{6}$. Os dados do universo ${ }^{7}$, agregados ao nível de setor censitário, permitiram compreender as diferenciações nos agrupamentos de favelas. Ou seja, se os dados fossem fornecidos em um nível de agregação maior, perceber as diferenciações se tornaria uma tarefa difícil, podendo inclusive comprometer os resultados. Da mesma maneira, se a pesquisa tivesse sido feita utilizando os microdados, poderíamos ter obtido um retrato mais fino das disparidades.

Utilizamos para o ano de 2010 a variável "Valor do rendimento nominal médio mensal das pessoas responsáveis por domicílios particulares permanentes (com e sem rendimento)" (IBGE, 2010a).

\footnotetext{
2 Ainda que os estudos na microescala ou escala do bairro sejam comuns na antropologia urbana, utilizando-se da etnografia, não são muito comuns nas pesquisas urbanas que utilizam métodos quantitativos.

${ }^{3}$ Apesar de a PCRJ admitir que alguns equipamentos localizados fora dos limites das favelas atendem os moradores, é sabido que barreiras físicas e/ou simbólicas podem impedir seu acesso em determinadas localidades. Portanto, neste trabalho foram considerados apenas os equipamentos localizados dentro dos limites estudados.

${ }^{4}$ Os empreendimentos do Programa Minha Casa Minha Vida podem ser entendidos como equipamentos sociais, na medida em que tem a prerrogativa de incentivar a construção de outros equipamentos públicos. Através do Fundo de Arrecadamento Residencial (FAR), é possível solicitar recursos para a construção de equipamentos públicos de educação, saúde e outros complementares à habitação. 0 recurso do FAR está limitado a 6\% (seis por cento) do valor da edificação e infraestrutura do empreendimento ao qual ele está vinculado (CAIXA, 2018).

5 PCRJ, Sistema de Assentamentos de Baixa Renda - SABREN, Secretaria de Educação, Secretaria de Habitação, Secretaria de Saúde.

${ }^{6}$ Esta base cartográfica é formada pela malha setorial e cada área estudada tem em média 60 setores censitários. 0 setor censitário é uma área delimitada pelo IBGE com aproximadamente 300 domicílios e que pode ser coberta por um único recenseador.

${ }^{7}$ Os dados do universo ou população são o conjunto de todos os indivíduos/elementos que fazem parte de determinada área de estudo. No caso do Censo, isto significa que todos os domicílios foram entrevistados. Os dados da amostra são colhidos para uma parte do universo. No caso da nossa pesquisa, não utilizamos nenhum dado feito por amostra, já que não seria possível identificar as diferenciações entre os setores na nossa escala de trabalho.
} 


\section{Áreas de estudo}

As três áreas estão localizadas em distintas regiões da cidade do Rio de Janeiro (Figura 1): Complexo do Alemão ("Zona Norte") e Rocinha ("Zona Sul") e Fazenda Coqueiro ("Zona Oeste"). A delimitação das áreas estudadas foi realizada a partir do limite dos bairros oficiais para Rocinha e Complexo do Alemão, uma vez que grande parte do bairro é considerada aglomerado subnormal pelo IBGE. Entretanto, para o Complexo da Fazenda Coqueiro, fez-se um recorte utilizando o limite de aglomerados subnormais ${ }^{8}$, delimitado pelo IBGE. Isso foi feito porque esta área se localiza dentro do bairro de Senador Camará, que tem tamanho incompatível com as escalas de análise dos outros dois casos: Rocinha e Complexo do Alemão.

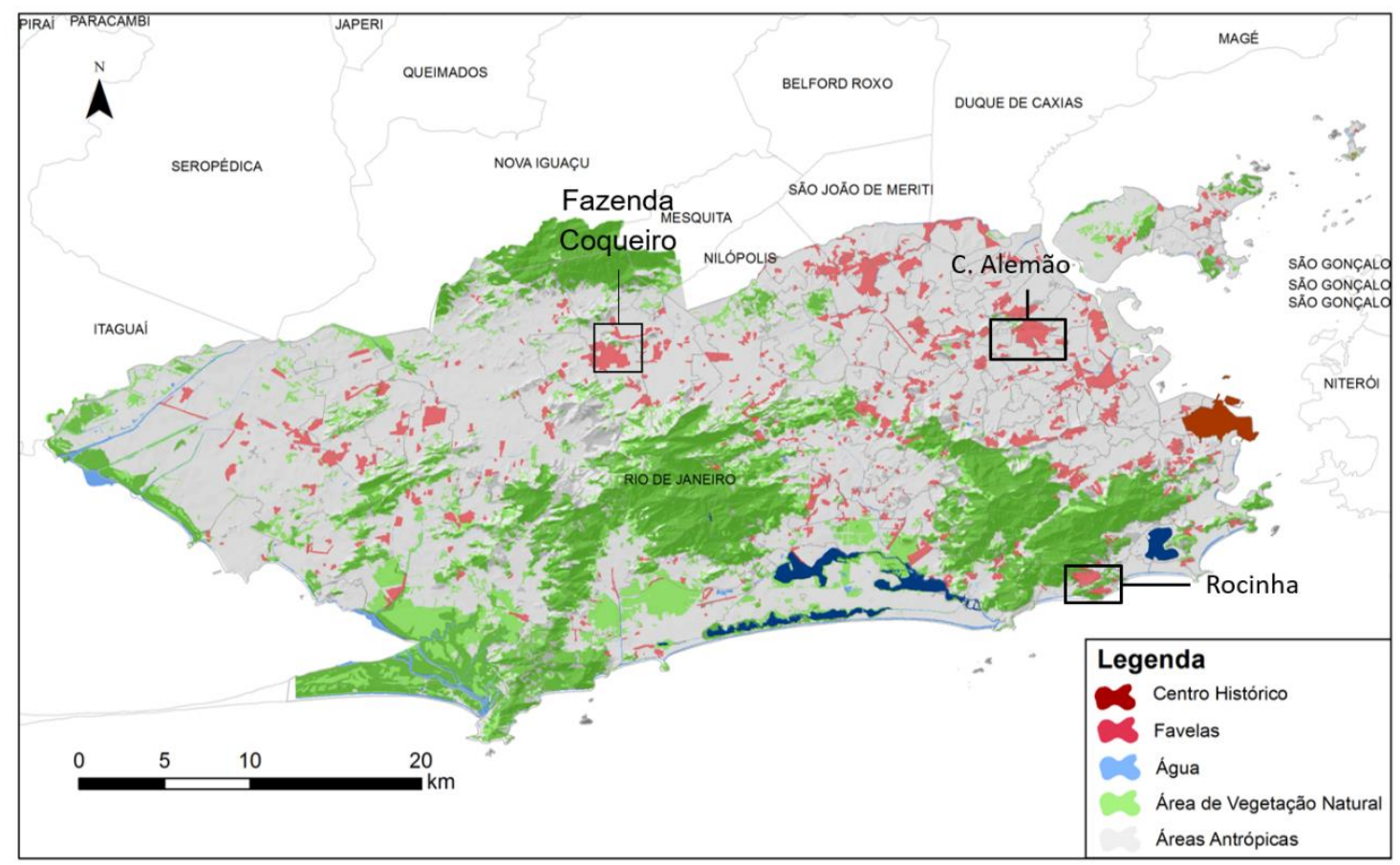

Figura 1 - Localização das áreas de estudo. Fonte: Elaboração própria com dados do IBGE (2010a).

O Complexo do Alemão foi reconhecido como bairro no ano de 1993. Está localizado junto à Serra da Misericórdia. Segundo dados do Censo de 2010 (IBGE, 2010a), os "aglomerados subnormais" dentro dos limites do bairro são os seguintes: Morro do Alemão, Vila Matinha, Morro das Palmeiras, Parque Alvorada, Nova Brasília, Joaquim de Queiroz, Itararé, Mourão Filho, Morro da Baiana, Morro do Adeus e Morro do Piancó.

Com cerca de 70 mil habitantes e 20 mil domicílios (IBGE, 2010a), o Complexo do Alemão é um dos bairros mais pobres da cidade. Segundo dados do Governo do Estado do Rio de Janeiro, conta com 29\% dos moradores vivendo abaixo da linha de pobreza (renda inferior a meio salário mínimo), o menor Índice de Desenvolvimento Humano (IDH) da cidade do Rio de Janeiro $(0,711)$ e renda per capita de $\mathrm{R} \$ 257,00$.

A Rocinha foi transformada em bairro também no ano de 1993. É formada por várias localidades conhecidas internamente pelos moradores. São elas: Morro da Roupa Suja, Macega, Campo da Esperança, Largo do Boiadeiro, Bairro Barcelos, Cidade Nova, Almir, Cachopa, Cachopinha, Curva do "S", Dioneia, Vila Verde, Vila União, Portão Vermelho, Capado, Terreirão, Faz Depressa, Vila Vermelha, Vila Cruzado e Vila Laboriaux (Toledo et al., 2014).

A Rocinha tem cerca de 70 mil habitantes e 25 mil domicílios (IBGE, 2010a). Por muitos anos foi considerada a maior favela da América Latina. Seu IDH é de 0,732, um dos mais baixos da cidade do Rio

\footnotetext{
8 É o conjunto constituído por 51 ou mais unidades habitacionais caracterizadas por ausência de título de propriedade e pelo menos uma das características abaixo: Irregularidade das vias de circulação e do tamanho e forma dos lotes e/ou carência de serviços públicos essenciais (como coleta de lixo, rede de esgoto, rede de água, energia elétrica e iluminação pública) (IBGE, 2010b).
} 
de Janeiro. Apesar disso, está localizada na área de maior renda da cidade - a Zona Sul, entre os bairros São Conrado e Gávea (com o maior IDH da cidade).

o Complexo da Fazenda Coqueiro está localizado no Bairro de Senador Camará, na Zona Oeste do Rio de Janeiro. 0 bairro possui IDH de 0,768, incluindo-se entre os 25 mais baixos dos 126 bairros da cidade. É composto por 15 favelas, a saber: Anne Dias, Bairro Nova Aliança, Caminho do Lúcio, Coreia, Fazenda Coqueiro, Jacaré, Jardim Clarice, Quinta do Taquaral, Retiro das Mangueiras, Rua Anne Dias, Travessa Santa Catarina, (Vila dos Mineiros), Vila Aliança (Loteamento da Rua do Lúcio), Vila Moreti e Vila Olímpica.

A Favela Fazenda Coqueiro, que deu nome ao Complexo, foi considerada pelo último Censo como a maior do Rio de Janeiro, retirando este posto da Rocinha. 0 Complexo do Alemão, todavia, continua sendo o maior aglomerado, quando se considera a extensão de todas as favelas que o compõem.

Trabalhar com três agrupamentos de favelas, localizados nessas três áreas distintas da cidade, se justifica na medida em que permite avaliar possíveis efeitos de localização. Isto é, compreender se a posição geográfica na cidade influencia, por exemplo, na quantidade de equipamentos e serviços. Nossa hipótese é de que a Rocinha, por exemplo - localizada na área de mais alta renda da cidade -, teria melhores condições socioeconômicas, além de mais equipamentos e serviços, em relação às outras áreas.

\section{Método}

O método consistiu na análise exploratória espacial da variável renda para as três áreas estudadas. Esta análise foi dividida em duas etapas. Na primeira foi empregado um teste para verificar se havia autocorrelação espacial para os setores estudados usando o Índice de Moran global. Este índice mede o nível de interdependência espacial para a região estudada, avaliando se o padrão é agrupado, disperso ou aleatório: quando positivo, representa uma tendência a agrupamento e, quando negativo, uma tendência à dispersão. Em outras palavras,

[...] o índice de Moran global presta-se a um teste cuja hipótese nula é de independência espacial; neste caso, seu valor seria zero. Portanto, valores positivos (entre 0 e +1 ) indicam para correlação direta, e negativos (entre 0 e -1), correlação inversa (Câmara \& Carvalho, 2004, p. 14).

As análises com este índice serviram para testar a hipótese de que havia um agrupamento de setores censitários com renda semelhante nas áreas estudadas. Associados ao índice também foram calculados o "p-valor" e o "z-score", que representam a significância estatística. Conhecer estes valores é importante para determinar se se deve ou não rejeitar a hipótese nula, pois neste caso a distribuição seria aleatória.

Após verificar o índice de correlação para a variável renda, foi iniciada a segunda fase da análise: a espacialização dos agrupamentos de renda com cálculo do Índice de Moran local. Este índice foi proposto por Anselin (1995) como uma ferramenta estatística para testar a autocorrelação local e para detectar objetos espaciais com influência no Índice de Moran global. Assim, enquanto o

[...] Índice de Moran global informa o nível de interdependência espacial entre todos os setores censitários em estudo, o Índice de Moran local avalia a covariância entre um determinado setor e uma certa vizinhança definida em função de uma distância d (Ramos, 1999, p. 3).

0 Índice de Moran local permite identificar agrupamentos (clusters) de setores censitários para os quais o comportamento da variável mencionada é sensível à vizinhança. Este procedimento regionaliza o conjunto de setores censitários identificando: (1) agrupamentos de setores com valores positivos da variável e a média dos setores vizinhos também positiva, denominados de alto-alto; (2) agrupamentos de setores com valores negativos da variável e a média dos setores vizinhos também negativa, denominados de baixo-baixo; (3) agrupamento de setores com valores positivos e a média a média dos setores vizinhos negativa, denominados de alto-baixo; e (4) agrupamentos de setores com valores negativos e a média dos setores vizinhos positivas, denominados de baixo-alto. Os dois primeiros indicam associação espacial positiva, no sentido de que uma localização possui vizinhos com valores semelhantes e os dois últimos 
indicam pontos de associação espacial negativa, no sentido de que uma localização possui vizinhos com valores distintos.

Para o Índice de Moran global utilizamos o software ArcGIS, e para o Índice de Moran local o Terraview, uma vez que este programa fornece uma análise mais robusta e oferece a espacialização do Índice de Moran local sem desprezar os resultados que tiveram uma baixa significância.

A partir da determinação dos grupos de renda, avaliamos a localização dos equipamentos e serviços em cada cluster de acordo com dados fornecidos pela PCRJ. Esta última análise foi adaptada do trabalho de Oakley \& Logan (2007). No método original, os autores utilizaram o Índice de Moran local para compreender a diferenciação entre os clusters de alta e baixa renda na cidade de Nova York. Os autores estavam interessados em compreender a quantidade e qualidade de serviços e equipamentos públicos existentes nos dois agrupamentos.

\section{Resultados e discussão}

O Índice de Moran global apresentou valores positivos para a variável renda nas três áreas, conforme apresentado na Tabela 1. Tanto o $z$-score quanto o $p$-valor indicaram uma tendência a agrupamento. Estes valores de significância indicam que há menos de $5 \%$ de probabilidade de que o padrão agrupado seja resultado do acaso.

Tabela 1 - Índice de Moran Global

\begin{tabular}{cccc}
\hline Área & $\begin{array}{c}\text { Índice de Moran } \\
\text { Global }\end{array}$ & z-score & p-valor \\
\hline Complexo do & 0,49 & 7,74 & 0,00 \\
Alemão & 0,12 & 2,00 & 0,05 \\
Rocinha & 0,17 & 2,22 & 0,03 \\
\hline
\end{tabular}

Fonte: Elaboração própria.

Estes resultados revelaram para todas as áreas valores positivos do Índice de Moran global, indicando estruturação socioespacial dos setores censitários segundo a variável renda. 0 Complexo do Alemão apresentou um valor mais alto para o índice, indicando um padrão de cluster mais consolidado. A Rocinha e a Fazenda Coqueiro apresentaram valores mais baixos, o que pode sugerir que não há um padrão tão claro de agrupamento entre os setores.

Todos os resultados apresentaram, também, significância relevante, sendo possível avançar para a segunda etapa da análise espacial: o Índice de Moran local. Nesta etapa, o objetivo foi identificar os clusters de renda em quatro classes: alto-alto, baixo-baixo, alto-baixo e baixo-alto.

Na Tabela 2, identificamos a média de renda de cada agrupamento em cada área estudada para os dois grupos de interesse: alto-alto (maior renda) e baixo-baixo (menor renda).

Tabela 2 - Média de Renda para cada cluster em reais

\begin{tabular}{ccc}
\hline Média Renda para ano de 2010 & Alto-alto & Baixo-baixo \\
\hline Complexo do Alemão & 795 & 504 \\
Rocinha & 766 & 563 \\
Fazenda Coqueiro & 775 & 534 \\
\hline
\end{tabular}

Fonte: Elaboração própria. 


\section{Complexo do Alemão}

Conforme pode ser visto na Figura 2, nossa análise indica que há no Complexo do Alemão uma separação entre dois grupos (clusters) de renda - em vermelho, o grupo de mais baixa renda, e em azul, o grupo de mais alta renda. 0 grupo de renda mais baixa localiza-se próximo à Serra da Misericórdia área que possui topografia muito acidentada e de mais difícil acesso. 0 grupo de maior renda coincide com a parte baixa do bairro, às margens da Estrada do Itararé, uma via importante que atravessa o bairro, oferecendo serviços de transporte, como pontos de ônibus.

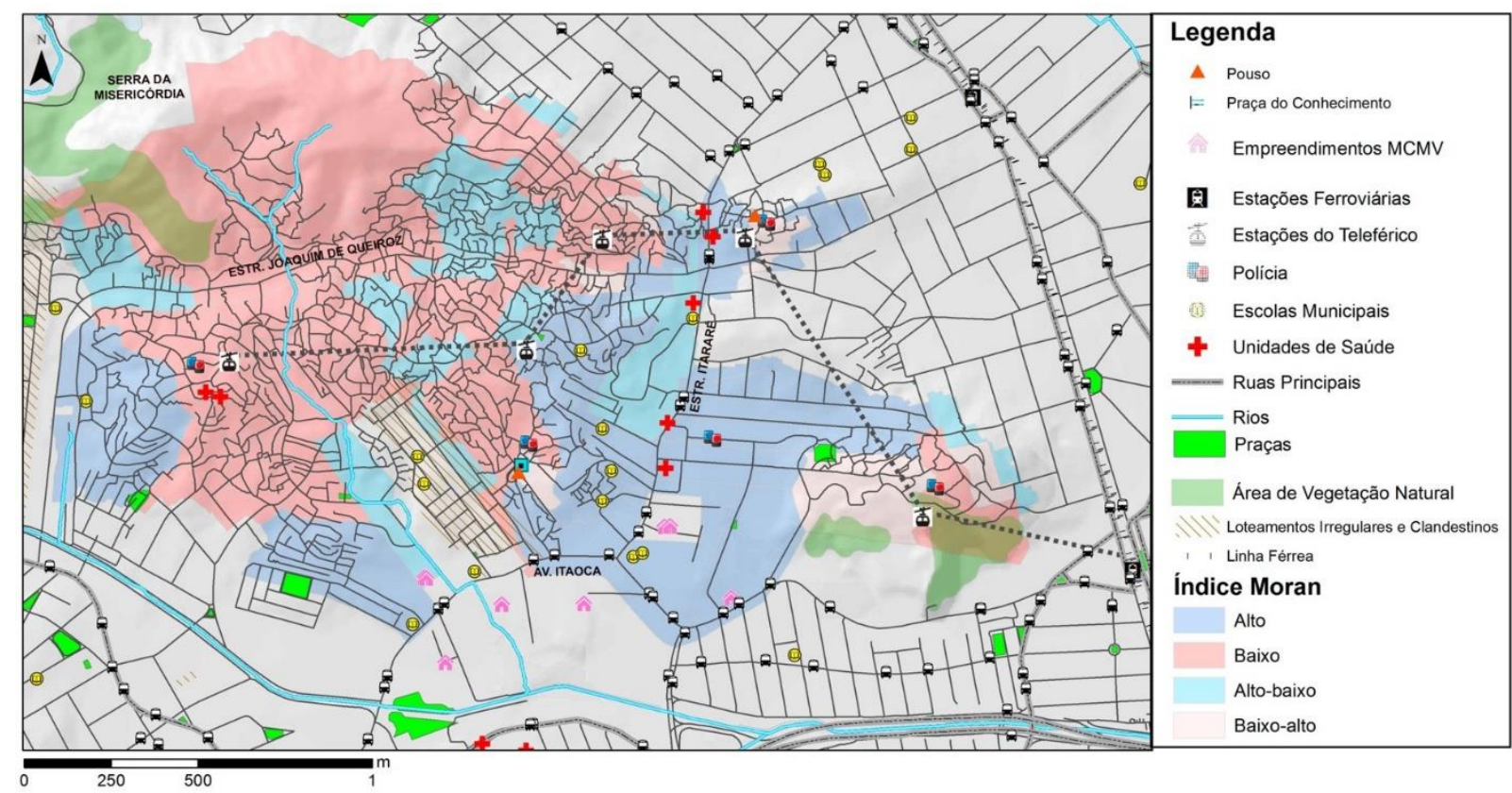

Figura 2 - Mapa de Localização dos equipamentos públicos no Complexo do Alemão. Fonte: Elaboração própria com dados do IBGE (2010a) e PCRJ (Rio de Janeiro, 2016).

De acordo com os dois grupos de renda, foram identificados a quantidade e os tipos de equipamentos e serviços em cada grupo. É possível observar uma concentração de alguns tipos de equipamentos importantes nos agrupamentos de mais alta renda.

No Complexo do Alemão, observa-se que as escolas e a maioria das unidades de saúde estão localizadas nas áreas de renda mais alta, assim como os empreendimentos do PMCMV também estão na porção mais favorecida. Consideradas como um serviço indesejável de se ter perto de casa, chama a atenção o número de Unidades de Polícia Pacificadora (UPP) localizadas no cluster de menor renda. Os outros equipamentos se distribuem de forma equivalente nos dois grupos de renda, como pode ser observado na Tabela 3.

Tabela 3 - Equipamentos e Serviços no Complexo do Alemão

\begin{tabular}{cccc}
\hline Complexo do Alemão & Alto-alto & Baixo-baixo & Total \\
\hline Escola Municipal & 9 & 0 & 9 \\
Unidades de Saúde & 5 & 2 & 7 \\
Praças & 5 & 4 & 9 \\
UPPs & 0 & 4 & 4 \\
Estações do Teleférico & 2 & 3 & 5 \\
Praça do Conhecimento & 0 & 1 & 1 \\
POUSO & 1 & 0 & 1 \\
MCMV & 3 & 0 & 3 \\
\hline
\end{tabular}

Fonte: Elaboração própria com dados do IBGE (2010a) e PCRJ (Rio de Janeiro, 2016). 


\section{Rocinha}

Na Rocinha também é possível observar uma separação entre dois grupos de renda. De acordo com o mapa da Figura 3, conseguimos identificar que o agrupamento de mais baixa renda é aquele localizado sobre o Túnel Zuzu Angel, uma região de difícil acesso, próximo ao Morro Dois Irmãos, que separa a Rocinha do Vidigal. 0 agrupamento de renda mais alta fica localizado na região de topografia menos acidentada que tem acesso pela Estrada da Gávea.

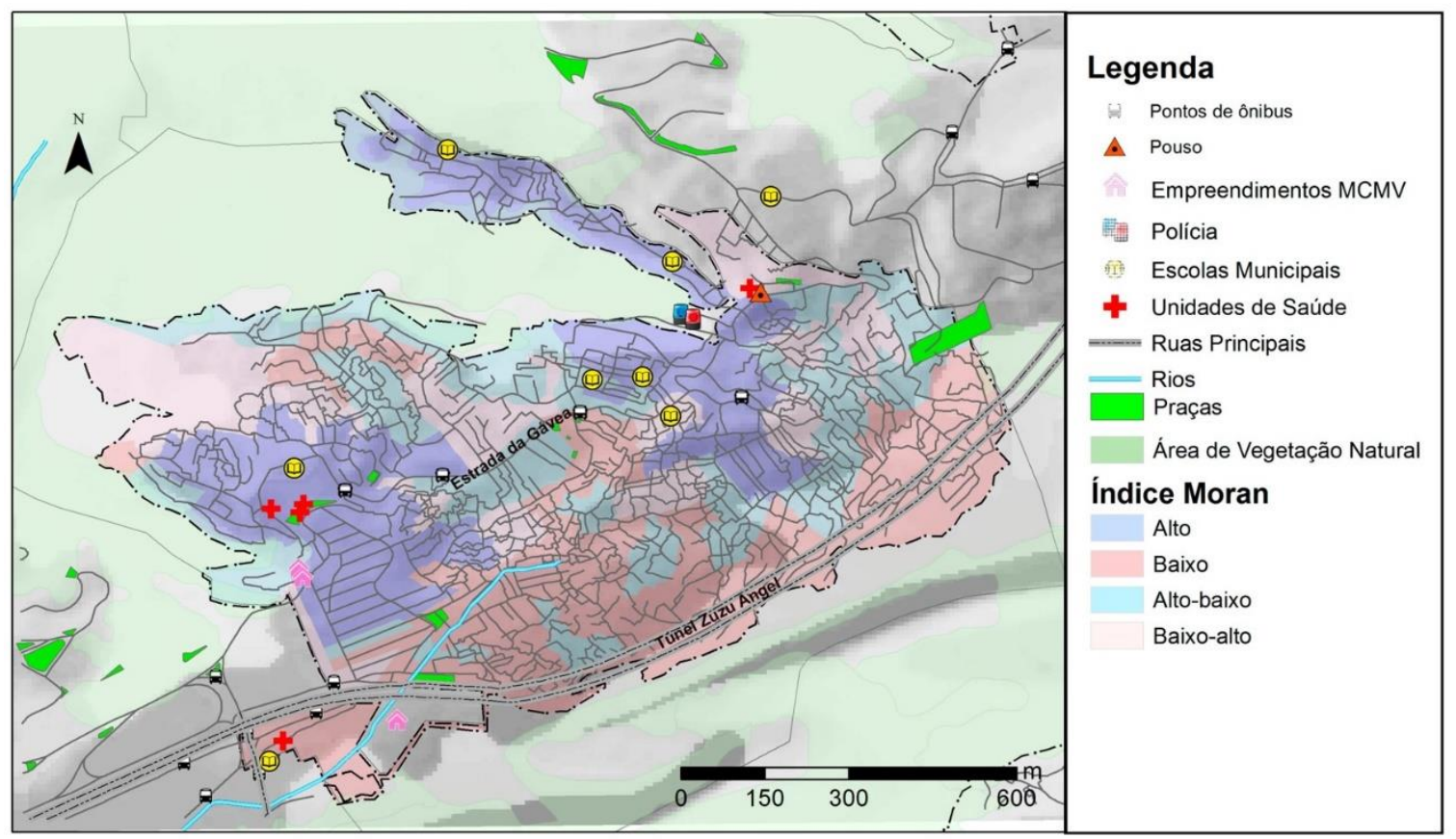

Figura 3 - Mapa de Localização dos equipamentos públicos na Rocinha. Fonte: Elaboração própria com dados do IBGE (2010a) e PCRJ (Rio de Janeiro, 2016).

Verificamos na Figura 3 o mesmo padrão de predominância dos equipamentos no cluster de maior renda, conforme observado no Complexo do Alemão. Ao longo da Estrada da Gávea estão localizados a maior quantidade de equipamentos e serviços, com exceção da UPP - bem como muitos estabelecimentos comerciais. Nesta parte da Rocinha estão os setores de maior renda (Tabela 4).

Tabela 4 - Equipamentos e Serviços na Rocinha

\begin{tabular}{cccc}
\hline Rocinha & Alto-alto & Baixo-baixo & Total \\
\hline Escola Municipal & 5 & 2 & 7 \\
Unidades de Saúde & 4 & 1 & 5 \\
Praças & 5 & 2 & 7 \\
UPPS & 1 & 0 & 1 \\
POUSO & 1 & 0 & 1 \\
MCMV & 2 & 0 & 2 \\
\hline
\end{tabular}

Fonte: Elaboração própria com dados do IBGE (2010a) e PCRJ (Rio de Janeiro, 2016).

\section{Fazenda Coqueiro}

A análise para a Fazenda Coqueiro também mostrou uma separação entre grupos de renda. Percebemos que a Estrada do Taquaral, onde está localizada a maioria dos estabelecimentos de comércio, não é tão determinante na divisão entre os grupos de renda, como nos dois casos anteriores. No Complexo da Fazenda Coqueiro, observamos uma divisão entre os grupos leste/oeste. 0 grupo de renda mais alta 
está a leste e o grupo de renda mais baixa a oeste. Na verdade, percebemos que a maioria dos equipamentos públicos está localizada fora dos limites das favelas. Na parte oeste há um maior número de loteamentos clandestinos e uma área verde remanescente, onde o grupo de menor renda se localiza. A porção norte é a área mais acidentada desta região e separa a Fazenda Coqueiro da Vila Kennedy. A localização dos equipamentos na Fazenda Coqueiro se mostrou menos desigual do que nas outras áreas estudadas (Figura 4 e Tabela 5). Isto porque, apesar de haver mais escolas no grupo de alta renda e a única unidade de saúde também estar localizada neste grupo, a discrepância não é tão grande entre os grupos como na Rocinha e no Complexo do Alemão.

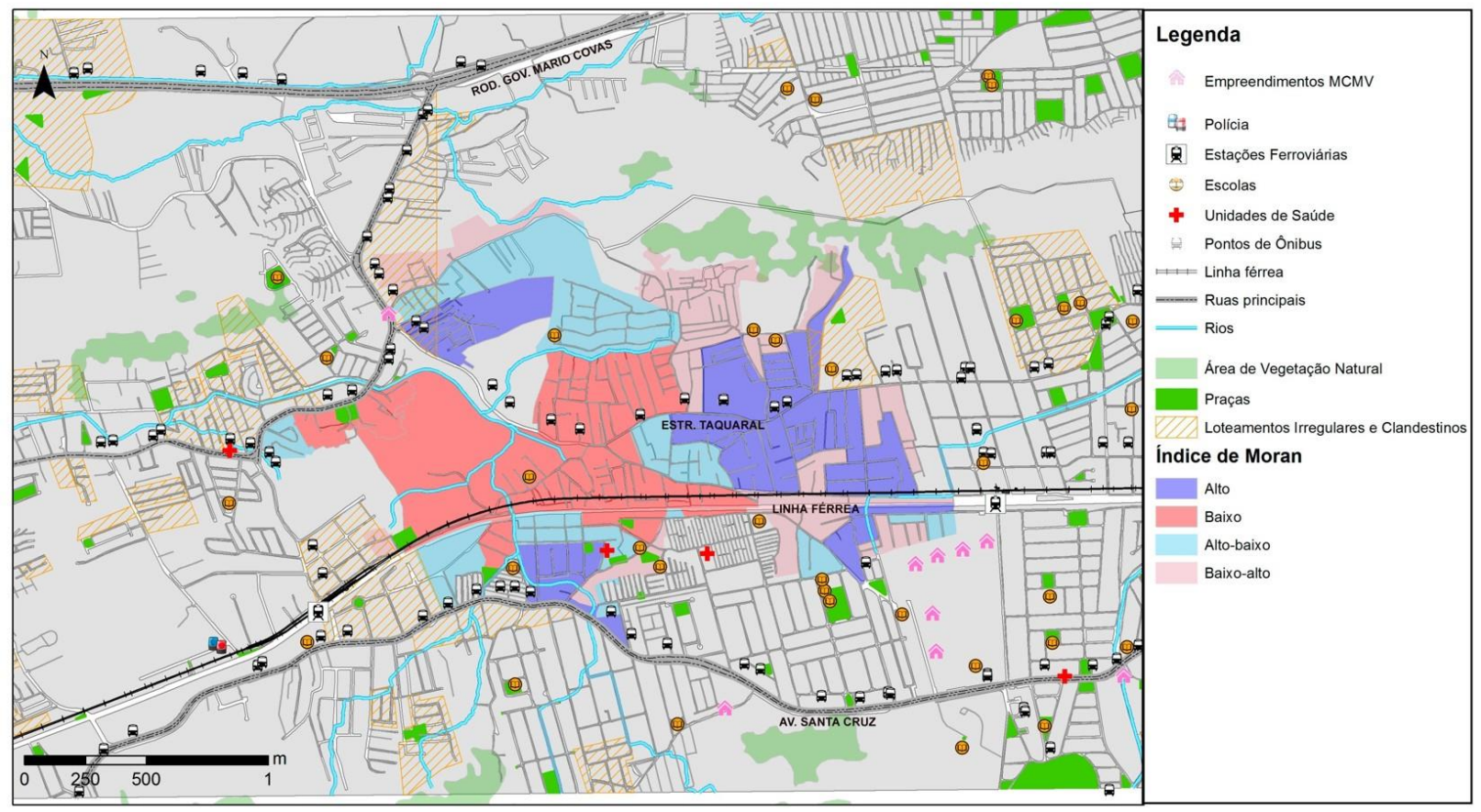

Figura 4 - Mapa de localização dos equipamentos na Fazenda Coqueiro. Fonte: Elaboração própria com dados do IBGE (2010a) e PCRJ (Rio de Janeiro, 2016).

Tabela 5 - Equipamentos e Serviços da Fazenda Coqueiro

\begin{tabular}{cccc}
\hline Fazenda Coqueiro & Alto-alto & Baixo-baixo & Total \\
\hline Escola Municipal & 7 & 5 & 12 \\
Unidades de Saúdle & 1 & 0 & 1 \\
Praças & 3 & 4 & 7 \\
\hline
\end{tabular}

Fonte: Elaboração própria com dados do IBGE (2010a) e PCRJ (Rio de Janeiro, 2016).

\section{Considerações finais}

Com este estudo, realizado na escala da favela, observa-se um padrão de concentração dos equipamentos de saúde, educação e demais projetos da Prefeitura nos agrupamentos de maior renda. 0 único equipamento onde houve maior concentração no grupo de menor renda foi a Unidade de Polícia Pacificadora. No Complexo do Alemão verificou-se que as quatro UPPs existentes foram ali implantadas. Este achado é importante porque as áreas de entorno imediato às UPPs geralmente oferecem risco para as pessoas que moram nas proximidades, pelos conflitos entre narcotraficantes e policiais. Isto poderia indicar que nas favelas repete-se a mesma lógica da cidade, onde os mais pobres são mais vulneráveis à violência urbana.

Verificamos que, assim como na cidade do Rio de Janeiro, os grupos de maior renda das favelas são beneficiados pela proximidade dos serviços públicos. Um breve exercício estatístico permite observar 
que, considerando a Rocinha, o Complexo do Alemão e a Fazenda Coqueiro, 61\% dos equipamentos de educação e $63 \%$ dos equipamentos de saúde estão localizados nas áreas de maior renda.

Em relação aos efeitos de localização, cabe destacar que o Complexo do Alemão (Zona Norte) é a área que conta com maior quantidade de equipamentos e diferentes tipos de serviços, seguido da Rocinha (Zona Sul). A Fazenda Coqueiro (Zona Oeste) apresenta o menor número de equipamentos públicos dentro de seus limites. Quanto à média de renda em cada cluster (Tabela 1), não há diferença considerável entre as áreas estudadas. Isto nos permite verificar que, apesar de estar localizada na Zona Sul da cidade, em meio a uma região de renda alta, a Rocinha não aufere "benefícios" por esta localização.

Quanto à estrutura espacial, observamos que as áreas mais pobres estão localizadas nas regiões mais acidentadas e de difícil acesso. No caso do Complexo do Alemão, o grupo de menor renda se localiza próximo à Serra da Misericórdia, enquanto, na Rocinha, os domicílios mais pobres localizam-se sobre o Túnel Zuzu Angel. Além disso, as áreas de renda mais alta coincidem com as áreas de ocupação mais antiga e que estão mais consolidadas, como a porção leste do Complexo do Alemão, a parte mais baixa da Rocinha e a porção sudoeste da Fazenda Coqueiro, onde está localizada a Favela do Jacaré.

Ainda que a Prefeitura considere que os equipamentos do entorno atendem às populações na favela, é sabido que existem barreiras físicas e simbólicas que muitas vezes podem inviabilizar o acesso a determinado serviço. Nesse sentido, a localização destes serviços públicos em localidades próximas pode fazer a diferença para muitas famílias. A implantação de equipamentos públicos nestas áreas poderia representar uma estratégia do ponto de vista do planejamento urbano, na medida em que poderia incentivar a melhoria na infraestrutura urbana.

Também é importante explorar o caráter publicitário das intervenções nas favelas, amplamente divulgadas por todas as esferas de governo envolvidas. A visão homogeneizante faz com que o discurso do Estado seja lido como uma forma de combater a pobreza. Intervir, seja na forma de infraestrutura urbana ou na dotação de equipamentos em áreas nas favelas que já possuem uma intervenção prévia e que têm relativamente melhores condições de infraestrutura, é reproduzir a desigualdade já existente e não combater a pobreza. Por isso, faz-se importante compreender a espacialidade das políticas públicas em escalas de estudo como as escalas do bairro e da favela. Este tipo de análise reforça o reconhecimento das favelas como lugares heterogêneos - que possuem uma diferenciação importante dentro dos seus limites.

Como síntese, no Rio de Janeiro, a estrutura urbana compreende a separação entre grupos sociais, de forma que os grupos de maior renda têm mais acesso a equipamentos e serviços. Os resultados deste trabalho indicam que a lógica de alocação dos recursos urbanos na cidade se replica nas favelas, na medida em que concentra a maioria dos equipamentos e serviços nas áreas de mais alta renda. Com a metodologia da análise espacial, foi possível mostrar que há uma complexidade na estrutura socioespacial das favelas, contribuindo para a desconstrução do estigma da favela como um lugar homogêneo da pobreza. Por fim, é importante reforçar que o Estado, através de suas políticas públicas urbanas, não tem considerado a espacialidade interna no momento da localização de equipamentos e serviços públicos - contribuindo com a ampliação da desigualdade na microescala.

\section{Referências}

Abreu, M. A. (2008). A evolução urbana do Rio de Janeiro (4. ed.). Rio de Janeiro: Instituto Pereira Passos.

Anselin, L. (1995). Local Indicators of Spatial Association (LISA). Geographical Analysis, 27(2), 93-115. http://dx.doi.org/10.1111/j.1538-4632.1995.tb00338.x.

Caixa Econômica Federal - CAIXA. (2018). Minha Casa Minha Vida: recursos FAR. Recuperado em 10 de junho de 2018, de http://www.caixa.gov.br/poder-publico/programas-uniao/habitacao/minha-casa-minhavida/Paginas/default.aspx

Câmara, G., \& Carvalho, M. (2004). Análise espacial de áreas. In S. Fucks, M. Carvalho, G. Câmara, \& A. M. Monteiro (Eds.), Análise espacial de dados geográficos (pp. 157-206). Brasília: EMBRAPA. 
Carvalho, C. (2017). Cidade e favela: transescalaridade das disparidades sociais? Revista Caminhos de Geografia, 18(63), 267-285. http://dx.doi.org/10.14393/RCG186312.

Fowler, C. S. (2016). Segregation as a multiscalar phenomenon and its implications for neighborhood-scale research: the case of South Seattle 1990-2010. Urban Geography, 37(1), 1-25. http://dx.doi.org/10.1080/02723638.2015.1043775. PMid:27041785.

Harvey, D. (1982). 0 trabalho, o capital e o conflito de classes em torno do ambiente construído nas sociedades capitalistas avançadas. Espaço e Debates, (6), 6-35.

Instituto Brasileiro de Geografia e Estatística - IBGE. (2010a). Censo demográfico. Recuperado em 2 de junho de 2015, de https://censo2010.ibge.gov.br/

Instituto Brasileiro de Geografia e Estatística - IBGE. (2010b). Censo demográfico: aglomerados subnormais/informações territoriais. Recuperado em 20 de julho de 2015, de

https://ww2.ibge.gov.br/home/estatistica/populacao/censo2010/aglomerados_subnormais_informacoes_territor iais/default_informacoes_territoriais.shtm

Kilroy, A. (2009). Intra-urban spatial inequality: cities as "urban regions. In World Bank (Ed.), World Development Report: reshaping economic geography. Washington: World Bank.

Lago, L. (2000). Desigualdades e segregação na metrópole: o Rio de Janeiro em tempos de crise (1. ed.). Rio de Janeiro: Revan: Fase.

Myrdal, G. (1957). Economic theory and underdeveloped regions. London: Duckworth.

Oakley, D., \& Logan, J. (2007). A Spatial analysis of the urban landscape: what accounts differences across neighborhoods? In L. Lobão, G. Hooks, \& A. Tickamyer (Eds.), The sociology of spatial inequality (pp. 215-230). New York: State University of New York.

Ramos, F. (1999). Indicadores de autocorrelação local em São Paulo (Monografia de especialização). Instituto Nacional de Pesquisas Espaciais, São Paulo.

Rio de Janeiro. Prefeitura Municipal. (2016). Sistema de Assentamento de Baixa Renda (SABREN). Recuperado em 15 de abril de 2016, de https://pcrj.maps.arcgis.com/home/item.html?id=4df92f92f1ef4d21aa77892acb358540

Schelling, T. C. (1978). Micromotives and macrobehavior. New York: Norton.

Toledo, L. C., Natividade, V., \& Vrcibradic, P. (2014). Repensando as habitações de interesse social. Rio de Janeiro: Letra Capital.

Vetter, D. M., \& Massena, R. M. (1982). Quem se apropria dos benefícios líquidos dos investimentos do Estado em infra-estrutura? Uma teoria de causação circular. In L. A. Machado da Silva (Ed.), Solo urbano: tópicos sobre o uso da terra (pp. 44-77). Rio de Janeiro: Zahar.

Villaça, F. (1998). Espaço Intra-urbano no Brasil (1. ed.). São Paulo: Studio Nobel.

\section{Editor: Fábio Duarte}

Recebido: Mar. 15, 2018

Aprovado: Ago. 12, 2018 